Nanostructured $\delta$ - $\mathrm{MnO}_{2} / \mathrm{Cd}(\mathrm{OH})_{2}$ heterojunction constructed at ambient conditions as sustainable cathodes for photocatalytic hydrogen production

Kaushik Natarajan ${ }^{\mathrm{a}}$, Mohit Saraf ${ }^{\mathrm{a}}$, Anoop K. Gupta ${ }^{\mathrm{b}}$ and Shaikh M. Mobin*a,b,c

aDiscipline of Metallurgy Engineering and Materials Science, biscipline of Chemistry, 'Discipline of Biosciences and Biomedical Engineering, Indian Institute of Technology Indore, Simrol, Khandwa Road, Indore 453552, India

*Email: xray@iiti.ac.in

Tel: +917312438762 
(a)

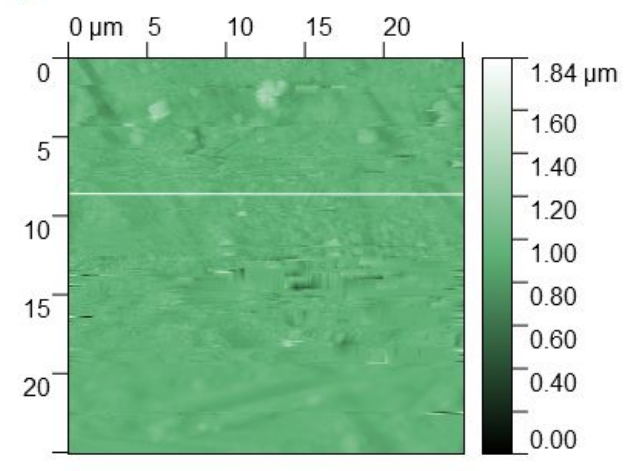

(b)

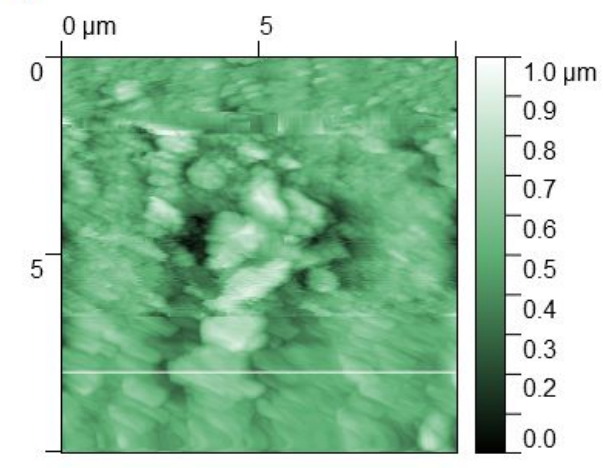

Figure S1. AFM analysis of (a) $\delta-\mathrm{MnO}_{2}$ and (b) $\delta-\mathrm{MnO}_{2} / \mathrm{Cd}(\mathrm{OH})_{2}$ thin film samples

The actual surface area and the surface roughness of some of the prepared samples have been estimated by AFM measurements as listed in Table $\mathbf{S 1}$ below. 
Table S1. AFM imaging results for the prepared samples

\begin{tabular}{ccccccc}
\hline Sample & $\begin{array}{c}\text { Image } \\
\text { area }\left(\boldsymbol{\mu m ^ { 2 }}\right)\end{array}$ & $\begin{array}{c}\text { Root-mean square } \\
\text { roughness, } \mathbf{R}_{\mathbf{q}} \\
(\mathbf{n m})\end{array}$ & $\begin{array}{c}\text { Average } \\
\text { roughness, } \\
\mathbf{R}_{\mathbf{a}} \\
(\mathbf{n m})\end{array}$ & $\mathbf{R}_{\mathbf{q}} / \mathbf{R}_{\mathbf{a}}$ & $\begin{array}{c}\text { Surface area } \\
\left(\boldsymbol{\mu m}^{2}\right)\end{array}$ & $\begin{array}{c}\text { Surface } \\
\text { roughness } \\
\mathbf{p a r a m e t e r} \\
\left(\mathbf{R}_{\mathbf{S}}\right)\end{array}$ \\
\hline$\delta-\mathrm{MnO}_{2}$ & 100 & 58.11 & 39.42 & 1.474 & 110.16 & 1.1016 \\
$\delta-\mathrm{MnO}_{2} / \mathrm{Cd}(\mathrm{OH})_{2}$ & 100 & 108.7 & 80.1 & 1.357 & 136.5 & 1.3650 \\
\hline
\end{tabular}

Data presented above indicates an increased surface area for the $\delta-\mathrm{MnO}_{2} / \mathrm{Cd}(\mathrm{OH})_{2}$ samples. 


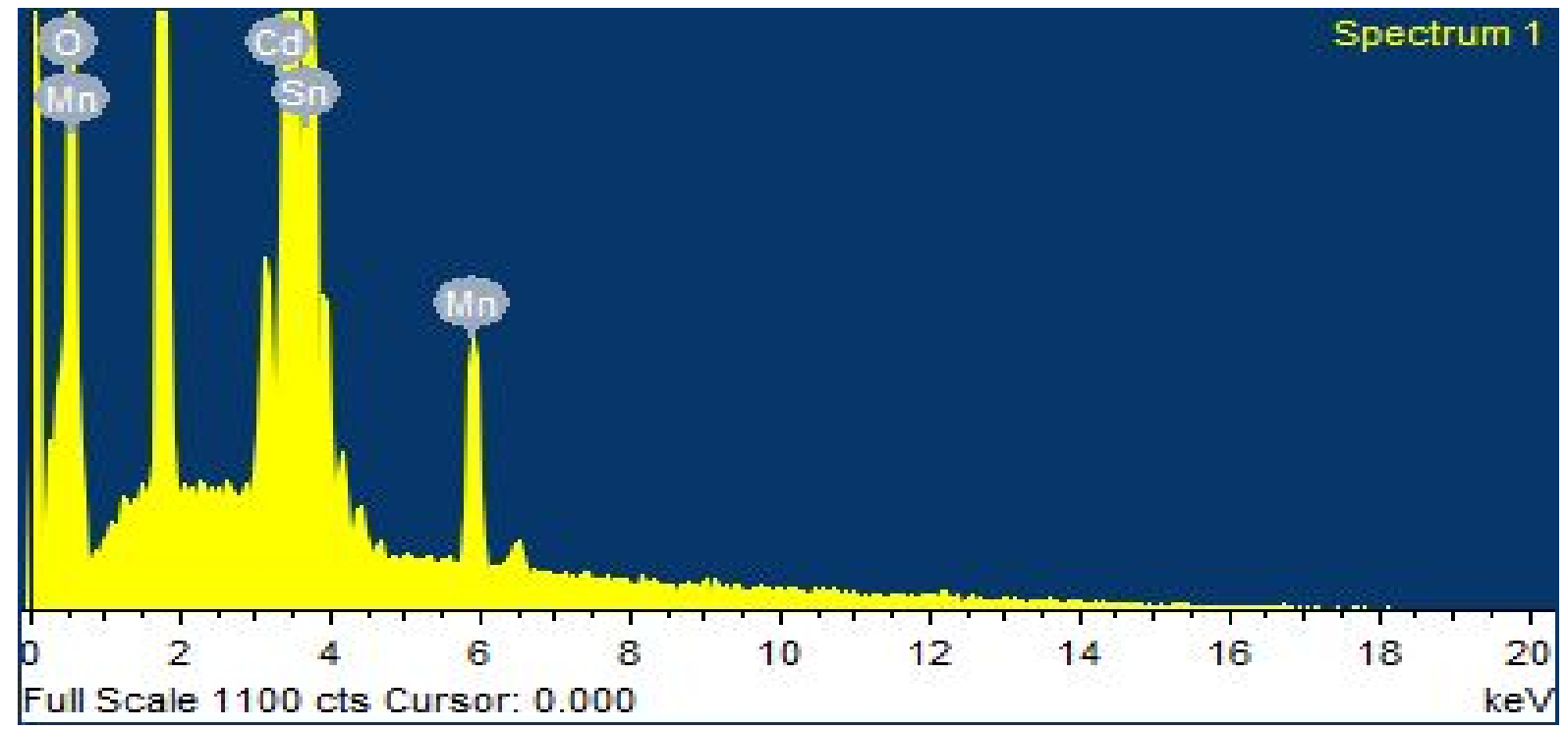

Standard :

Mn Mn 1-Jun-1999 12:00 AM

Cd Cd 1-Jun-1999 12:00 AM

Sn Sn 1-Jun-1999 12:00 AM

\begin{tabular}{l|llll}
\hline Element & Weight $\%$ & Atomic\% & Compd\% & Formula \\
& & & & \\
$\mathrm{Mn} \mathrm{K}$ & 7.37 & 6.59 & 9.52 & $\mathrm{MnO}$ \\
$\mathrm{Cd} \mathrm{L}$ & 6.98 & 3.05 & 7.98 & $\mathrm{CdO}$ \\
$\mathrm{Sn} \mathrm{L}$ & 64.98 & 26.90 & 82.50 & $\mathrm{SnO} 2$ \\
$\mathrm{O}$ & 20.66 & 63.45 & & \\
Totals & 100.00 & & & \\
\hline
\end{tabular}

Figure S2. EDX analysis result for the as-prepared $\delta-\mathrm{MnO}_{2} / \mathrm{Cd}(\mathrm{OH})_{2}$ thin films on FTO glass.

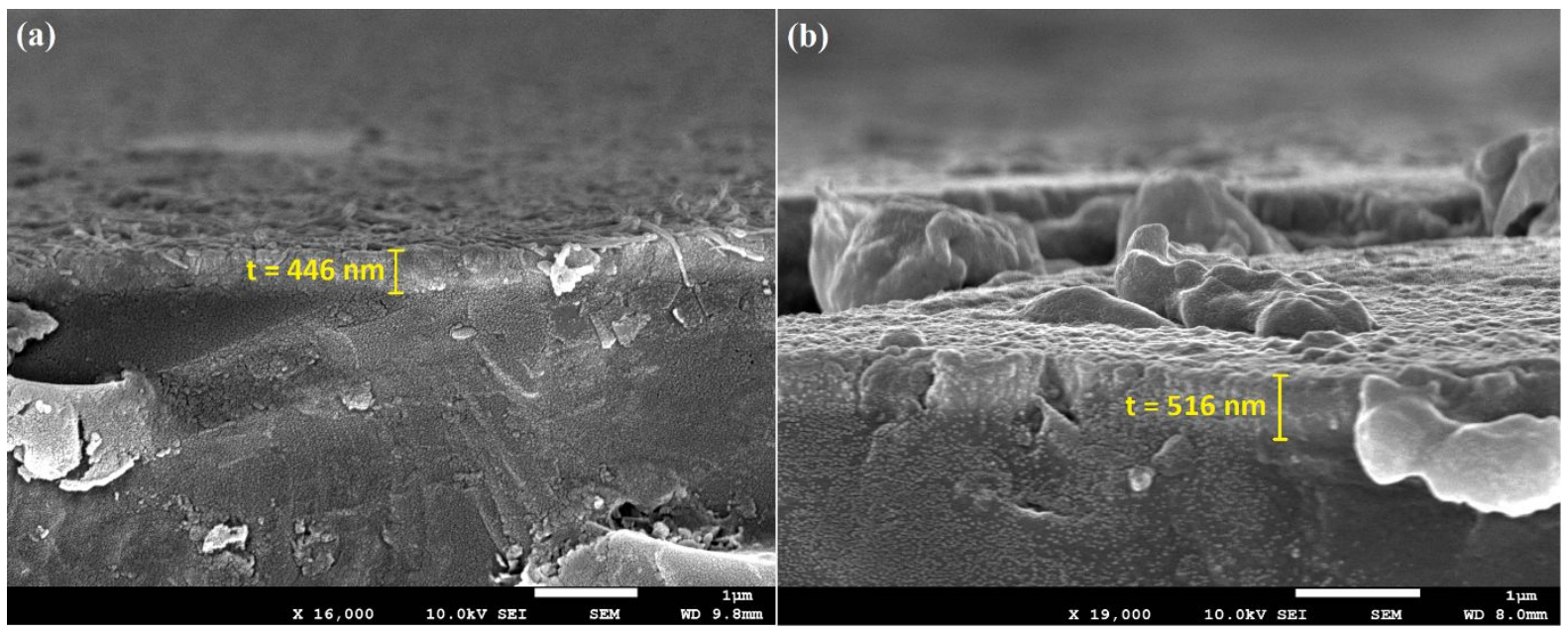

Figure S3. SEM image analysis for thickness calculation of (a) $\delta-\mathrm{MnO}_{2}$ and (b) $\delta$ $\mathrm{MnO}_{2} / \mathrm{Cd}(\mathrm{OH})_{2}$ thin films 


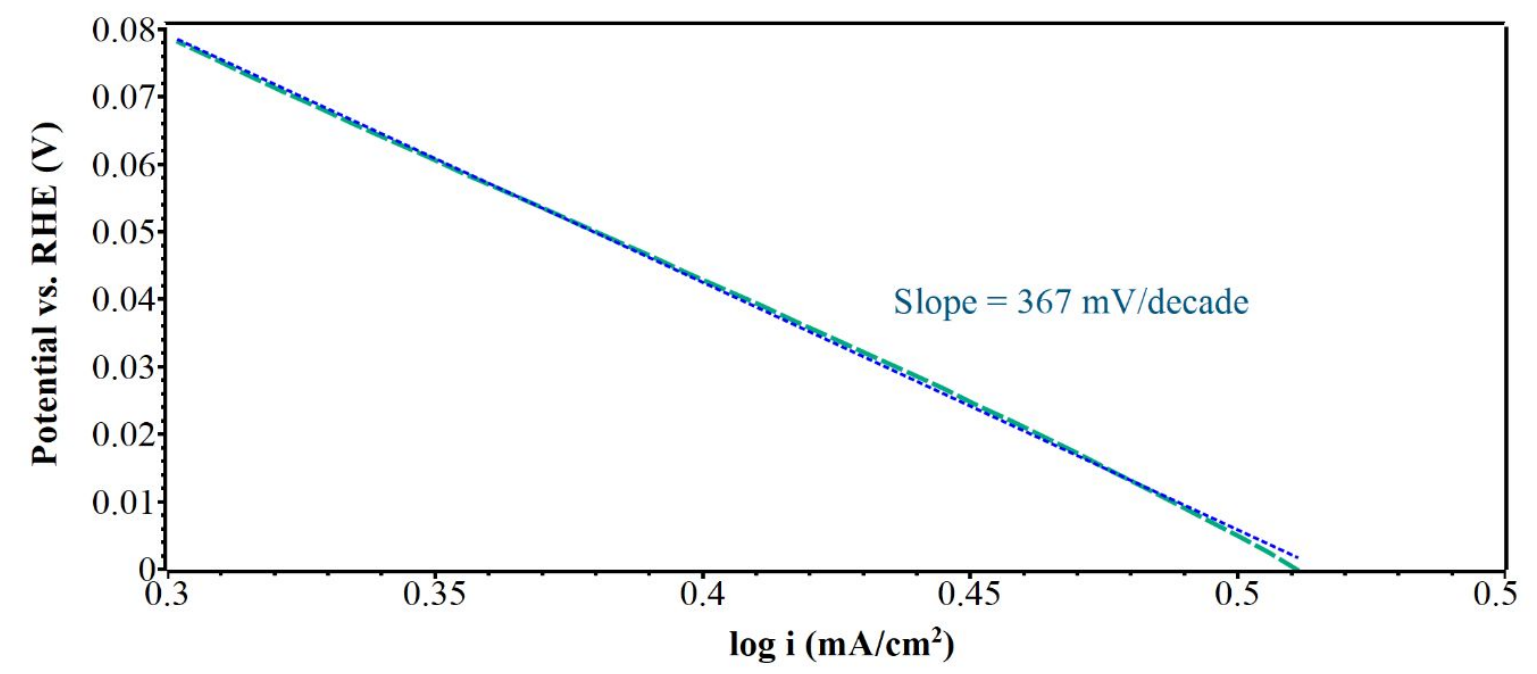

Figure S4. Tafel slope plotted against the rising part of the photocurrent. ${ }^{1}$ 


\section{Stability Testing}

Photocurrent stability was tested at $0.2 \mathrm{~V}$ vs. RHE by using chronoamperometry to observe the decay of photocurrent over time in a standard three-electrode electrochemical cell comprising of $1 \mathrm{M} \mathrm{Na}_{2} \mathrm{SO}_{4}$ with $\mathrm{pH}$ adjusted to 4.0 as the electrolyte, $\mathrm{Ag} / \mathrm{AgCl}$ reference electrode, $\mathrm{Pt}$ counter electrode and $\delta-\mathrm{MnO}_{2} / \mathrm{Cd}(\mathrm{OH})_{2}$ as the working electrode with $1000 \mathrm{~W} / \mathrm{m}^{2}$ light source as described in main manuscript and $25{ }^{\circ} \mathrm{C}$ ambient temperature. It is observed that approximately $76 \%$ of initial photocurrent is retained after 8000 seconds of testing. The results may be seen below.

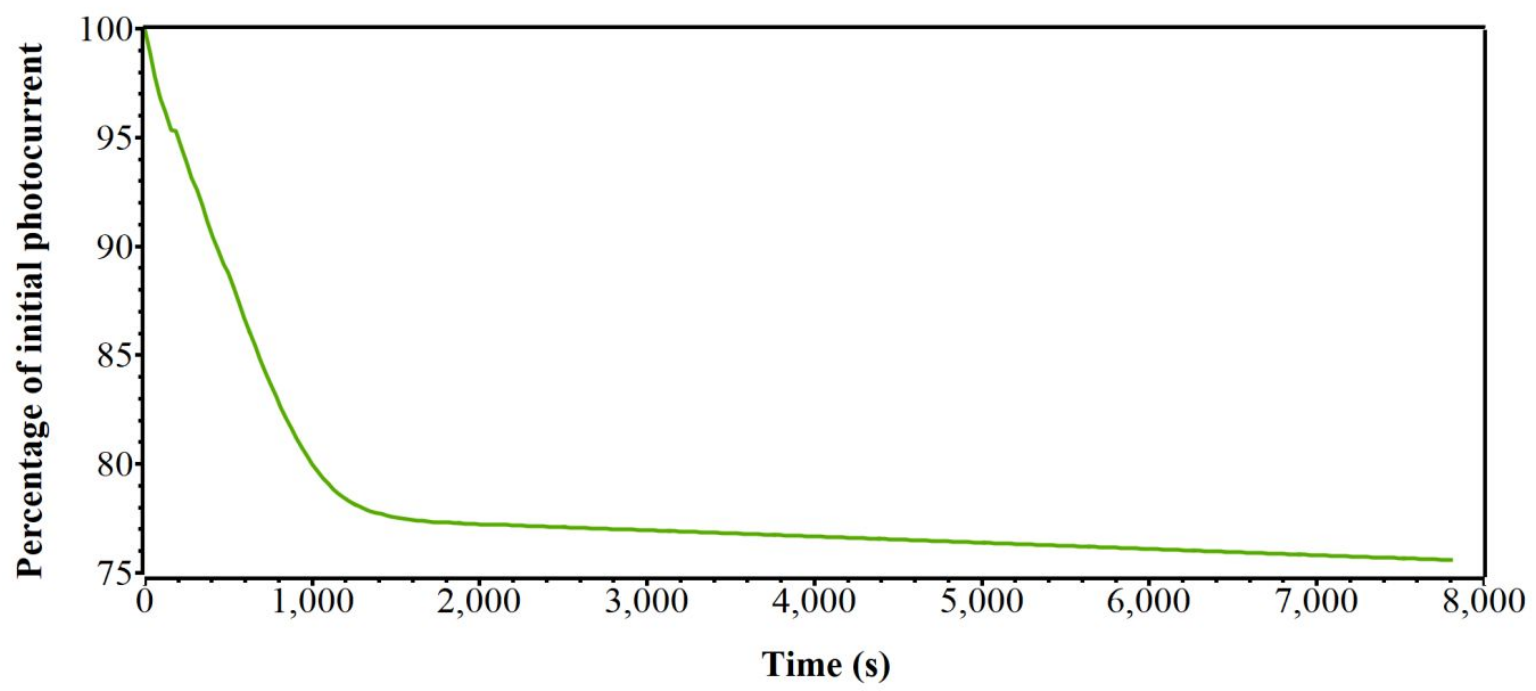

Figure S5. Chronoamperometric curve expressed as percentage of initial photocurrent over time for $\delta-\mathrm{MnO}_{2} / \mathrm{Cd}(\mathrm{OH})_{2}$ thin film on FTO glass substrate. 

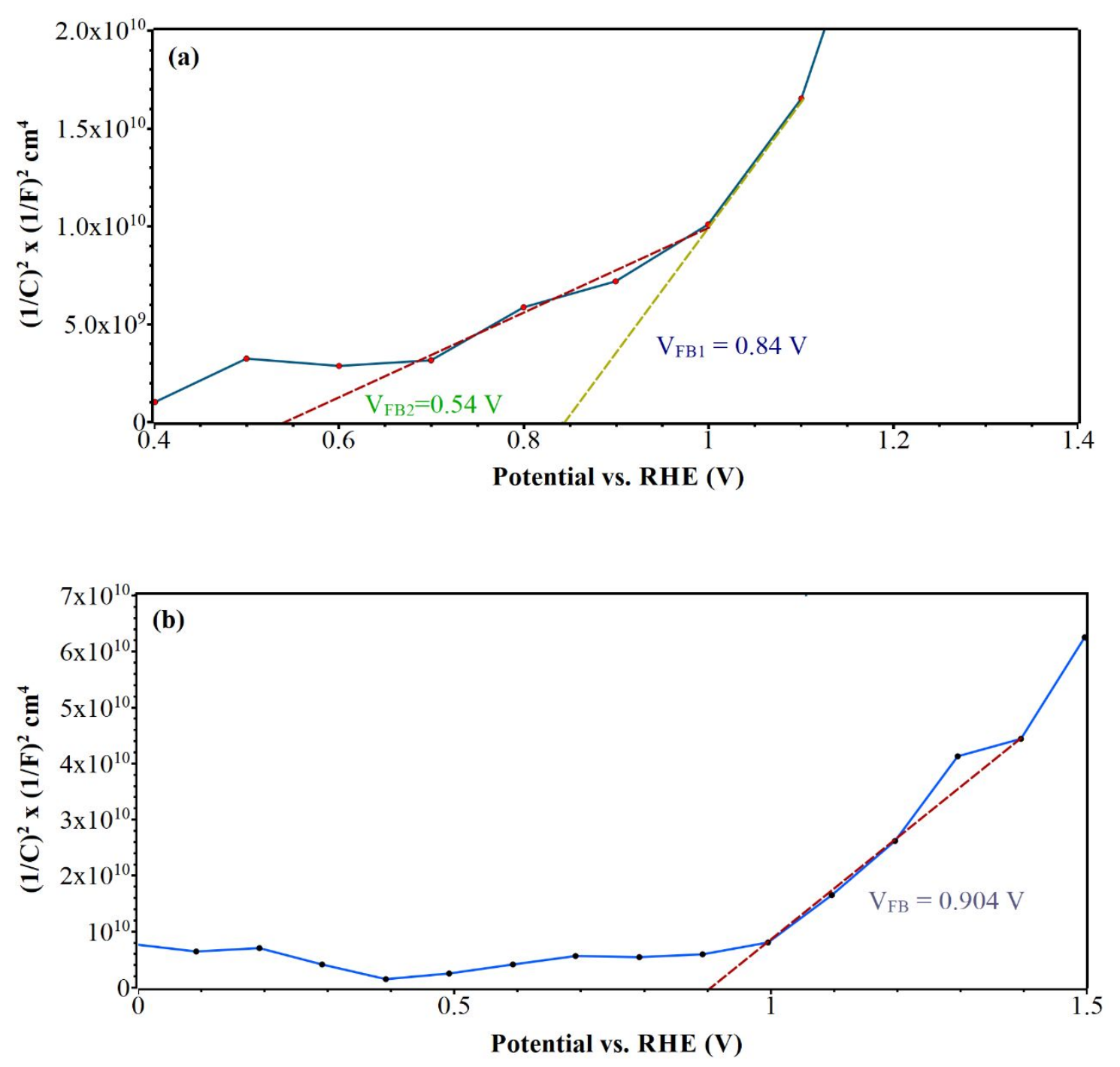

Figure S6. Mott-Schottky plots of $\delta-\mathrm{MnO}_{2} / \mathrm{Cd}(\mathrm{OH})_{2}$ films (a) in dark and (b) in illumination. 

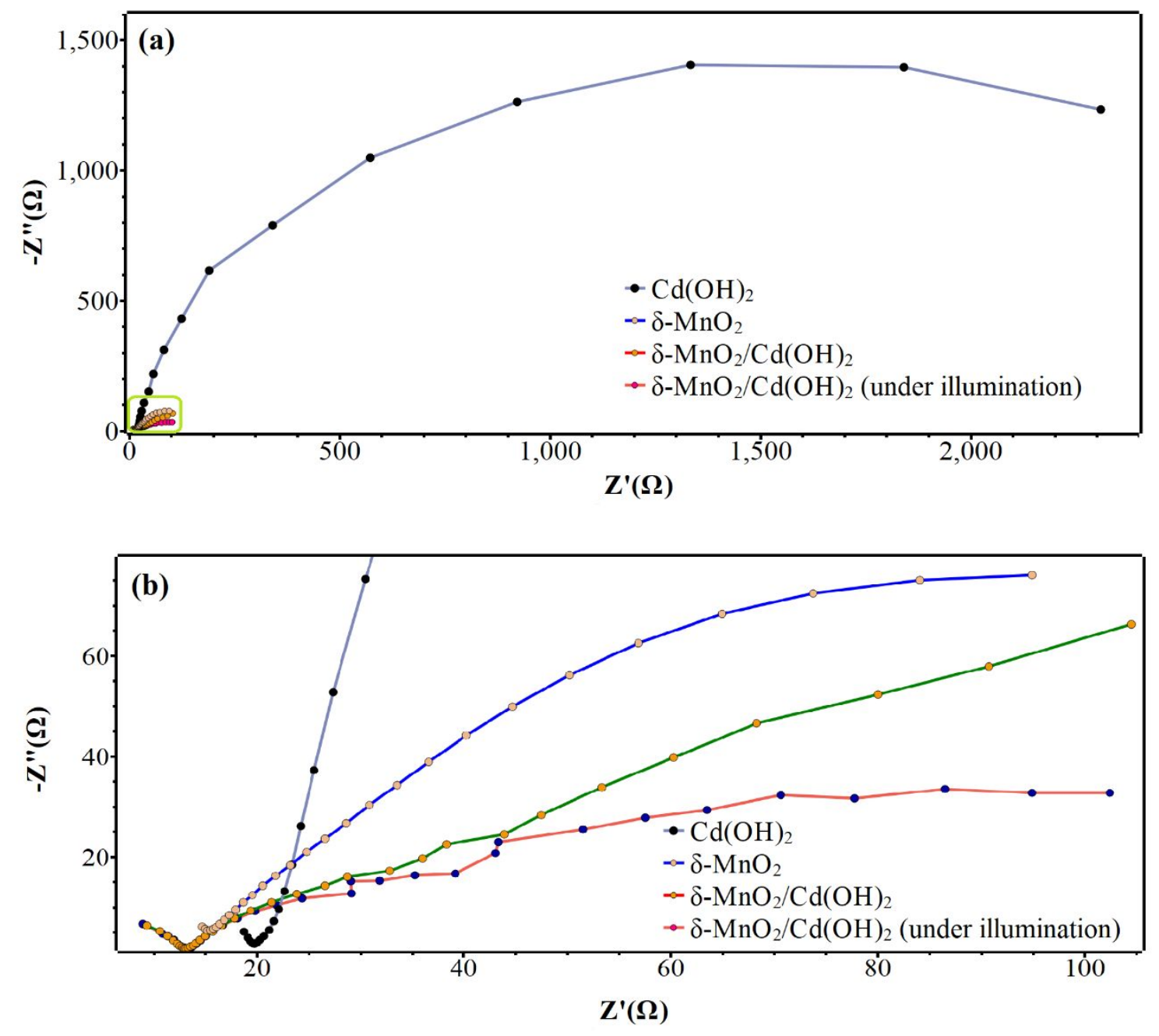

Figure S7. (a) Electrochemical Impedance Spectra of thin films of $\mathrm{Cd}(\mathrm{OH})_{2}, \delta-\mathrm{MnO}_{2}, \delta$ $\mathrm{MnO}_{2} / \mathrm{Cd}(\mathrm{OH})_{2}$ and $\delta-\mathrm{MnO}_{2} / \mathrm{Cd}(\mathrm{OH})_{2}$ under $\mathrm{AM} 1.5 \mathrm{G}$ illumination. (b) Close-up view of boxed portion of Electrochemical Impedance Spectra as shown in (a). 


\section{XPS Acquisition Parameters}

\section{A. Survey Scan}

\begin{tabular}{|l|l|}
\hline Acquisition Parameters : & \\
\hline Parameter & \\
\hline Total acquisition time & 54.4 secs \\
\hline Number of Scans & \\
\hline Source Gun Type & Al K Alpha \\
\hline Spot Size & $900 \mu \mathrm{m}$ \\
\hline Lens Mode & Standard \\
\hline Analyser Mode & CAE : Pass Energy $120.0 \mathrm{eV}$ \\
\hline Energy Step Size & 1.000 eV \\
\hline Number of Energy Steps & \\
\hline
\end{tabular}

B. C 1s scan

\begin{tabular}{|l|l|}
\hline Acquisition Parameters : & \\
\hline Parameter & \\
\hline Total acquisition time & 1 mins 35.2 secs \\
\hline Number of Scans & \\
\hline Source Gun Type & Al K Alpha \\
\hline Spot Size & $900 \mu \mathrm{m}$ \\
\hline Lens Mode & Standard \\
\hline Analyser Mode & CAE : Pass Energy 20.0 eV \\
\hline Energy Step Size & 0.050 eV \\
\hline Number of Energy Steps & \\
\hline
\end{tabular}

\section{O 1s scan}

\begin{tabular}{|l|l|}
\hline Acquisition Parameters : & \\
\hline Parameter & \\
\hline Total acquisition time & 1 mins 40.2 secs \\
\hline Number of Scans & \\
\hline Source Gun Type & Al K Alpha \\
\hline Spot Size & $900 \mu \mathrm{m}$ \\
\hline Lens Mode & Standard \\
\hline Analyser Mode & CAE : Pass Energy 20.0 eV \\
\hline Energy Step Size & 0.050 eV \\
\hline Number of Energy Steps & \\
\hline
\end{tabular}


D. Mn 2p scan

\begin{tabular}{|l|l|}
\hline Acquisition Parameters : & \\
\hline Parameter & \\
\hline Total acquisition time & 2 mins 30.2 secs \\
\hline Number of Scans & \\
\hline Source Gun Type & Al K Alpha \\
\hline Spot Size & $900 \mu \mathrm{m}$ \\
\hline Lens Mode & Standard \\
\hline Analyser Mode & CAE : Pass Energy 20.0 eV \\
\hline Energy Step Size & 0.050 eV \\
\hline Number of Energy Steps & \\
\hline
\end{tabular}

E. Cd 3d scan

\begin{tabular}{|l|l|}
\hline Acquisition Parameters : & \\
\hline Parameter & \\
\hline Total acquisition time & 1 mins 40.2 secs \\
\hline Number of Scans & \\
\hline Source Gun Type & Al K Alpha \\
\hline Spot Size & $900 \mu \mathrm{m}$ \\
\hline Lens Mode & Standard \\
\hline Analyser Mode & CAE : Pass Energy 20.0 eV \\
\hline Energy Step Size & $0.050 \mathrm{eV}$ \\
\hline Number of Energy Steps & \\
\hline
\end{tabular}


Standard JCPDS cards for $\delta-\mathrm{MnO}_{2}$ and $\mathrm{Cd}(\mathrm{OH})_{2}$

A. $\delta-\mathrm{MnO}_{2}(\mathrm{JCPDS} \# 42-1317)$

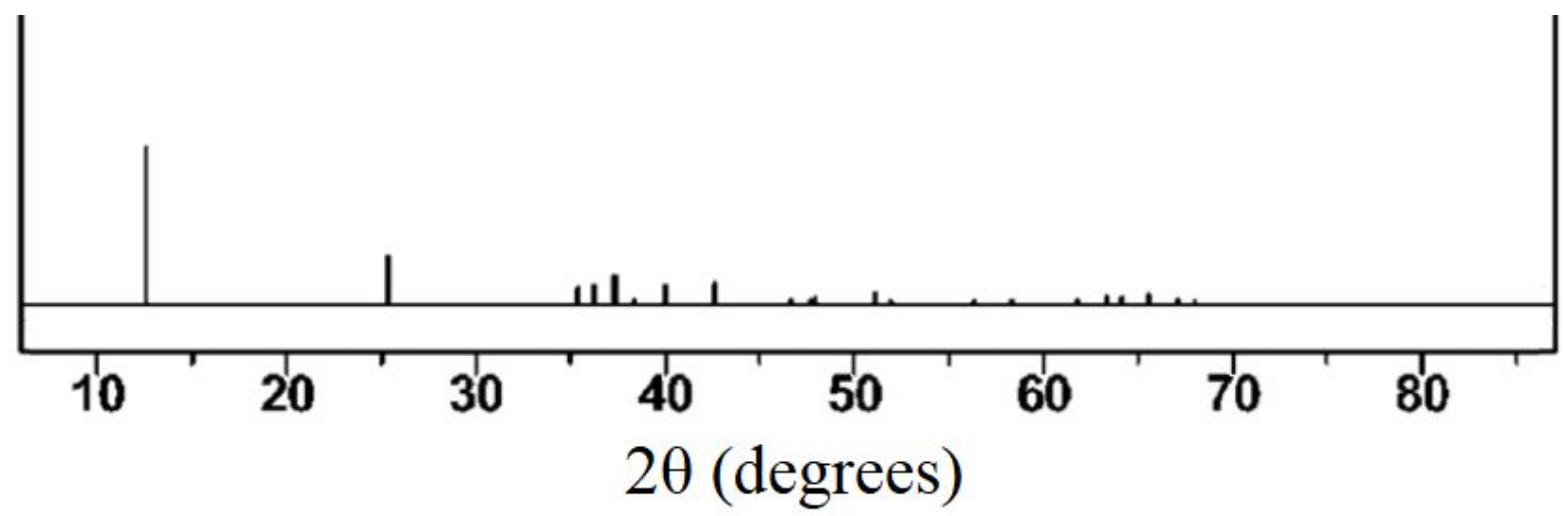

B. $\mathrm{Cd}(\mathrm{OH})_{2}-$ hexagonal (JCPDS \#31-0228)

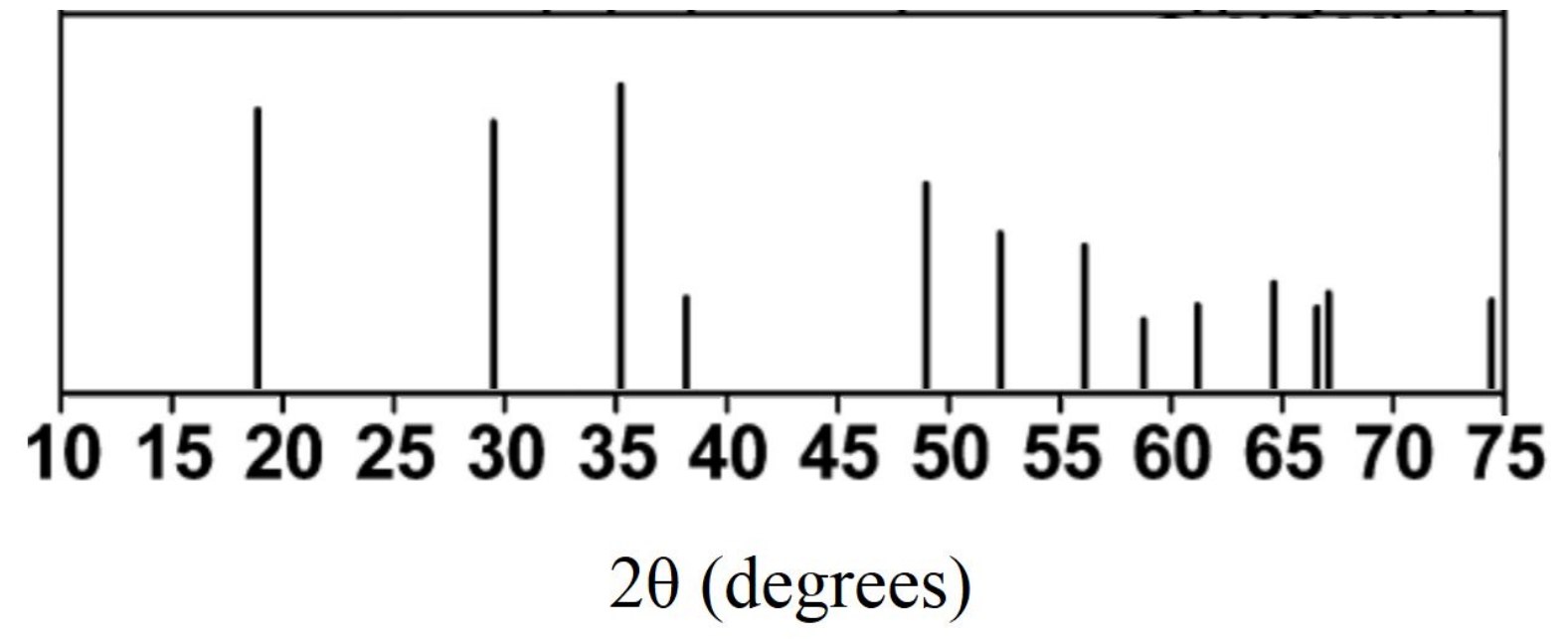

C. $\mathrm{Cd}(\mathrm{OH})_{2}-$ monoclinic (JCPDS \#20-0179)

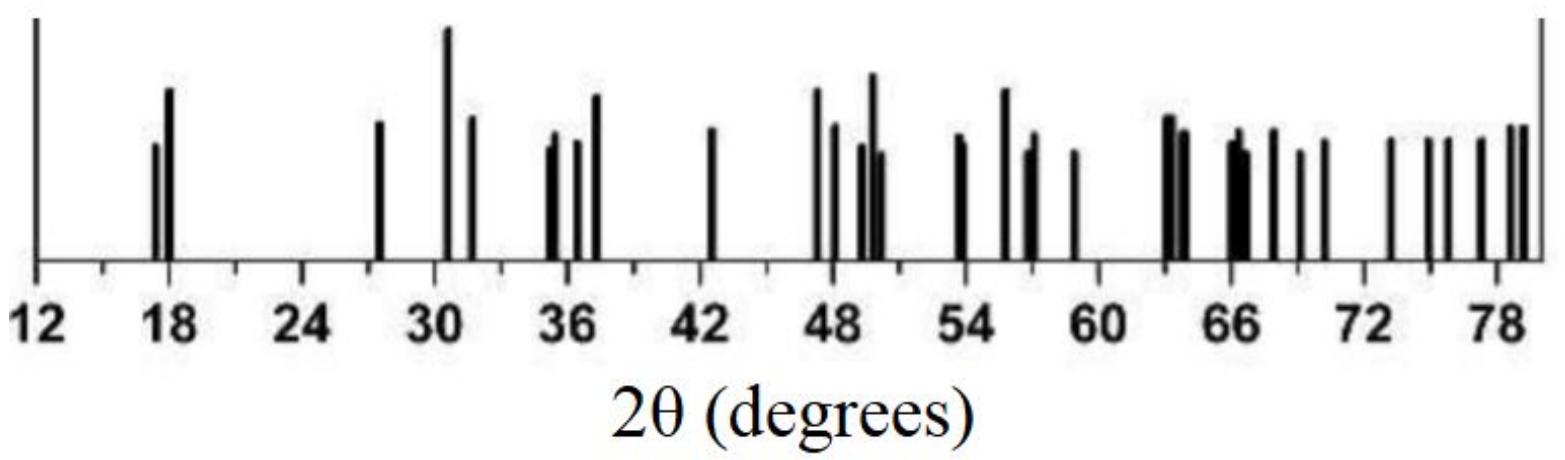




\section{Calculation of Faradaic Efficiency}

Faradaic Efficiency Test was performed using the same apparatus as described in our previous works. $^{2,3}$ Briefly, the setup comprises of three sealed chambers: (1) A glass chamber comprising of three electrode cell in which gas production is observed; (2) A gas transfer compartment and (3) a water displacement cell consisting of a marked cylinder with $100 \mu \mathrm{L} / 0.1$ $\mathrm{mL}$ increments.

The solutions in the reaction cell and gas transfer compartments were initially saturated with oxygen and hydrogen gases. After this, the electrochemical reaction was started using $\delta$ $\mathrm{MnO}_{2} / \mathrm{Cd}(\mathrm{OH})_{2}$ as the working electrode, a Pt counter electrode and an $\mathrm{Ag} / \mathrm{AgCl}$ reference electrode. A suitable negative voltage was given to initiate hydrogen production, in the presence of suitable light source (intensity $1000 \mathrm{~W} / \mathrm{m}^{2}$, AM $1.5 \mathrm{G}$ ). The production of hydrogen gas causes a change in the water level of the graduated cylinder.

After appropriately correcting for the contributions from vapour pressure of water in the containers, the proportion of hydrogen gas obtained was almost identical to our previous report on $\mathrm{Cu}-\delta-\mathrm{MnO}_{2}$ based electrodes at about $320 \mu \mathrm{L}$ corresponding to $14.28 \mu \mathrm{mol}$ of $\mathrm{H}_{2}$ gas produced with a $91.89 \%$ Faradaic efficiency considering the effects of water vapour as described in our previous work.

\section{Conversion from $\mathrm{Ag} / \mathrm{AgCl}$ scale to RHE scale}

For all electrochemical measurements, the Nernst equation was used to draw equivalent scale from $\mathrm{Ag} / \mathrm{AgCl}$ to RHE:

$$
E_{\text {RHE }}=E_{\text {Ag/ } / \mathrm{ggCl}}+0.059 \mathrm{pH}+E_{\mathrm{Ag} / \mathrm{AgCl}}^{o}
$$

\section{References}

(1) Kim, Y. B.; Kim, J. S.; Baek, S. K.; Yun, Y. D.; Cho, S. W.; Jung, S. H.; Cho, H. K. Electrochemical Surface Charge-Inversion from Semi-Insulating $\mathrm{Sb}_{2} \mathrm{Se}_{3}$ Photoanodes and Abrupt Photocurrent Generation for Water Splitting. Energy Environ. Sci. 2018, 11 (9), 2540-2549. https://doi.org/10.1039/C8EE00923F.

(2) Natarajan, K.; Gupta, A. K.; Ansari, S. N.; Saraf, M.; Mobin, S. M. Mixed-LigandArchitected 2D Co(II)-MOF Expressing a Novel Topology for an Efficient Photoanode for Water Oxidation Using Visible Light. ACS Appl. Mater. Interfaces 2019, 11 (14), 13295-13303. https://doi.org/10.1021/acsami.9b01754.

(3) Natarajan, K.; Saraf, M.; Mobin, S. M. Visible Light Driven Water Splitting through an Innovative $\mathrm{Cu}$-Treated- $\delta-\mathrm{MnO}_{2}$ Nanostructure: Probing Enhanced Activity and Mechanistic Insights. Nanoscale 2018, 10 (27), 13250-13260. 
https://doi.org/10.1039/C8NR03027H. 